\title{
(e) Anstrumento
}

ISSN 1984-5499

Licenciado sob uma Licença Creative Commons

\section{Contributos da supervisão pedagógica para a formação docente em Portugal}

\author{
Contributions of pedagogical supervision to teacher training in Portugal
}

\section{Contribuciones de la supervisión pedagógica a la formación del profesorado en Portugal}

\author{
Elza Mesquita ${ }^{1}$ \\ Subcoordenadora e Investigadora integrada do Instituto Politécnico de Bragança / Bragança, Portugal \\ Angelina Sanches ${ }^{2}$ \\ Investigadora integrada do Instituto Politécnico de Bragança / Bragança, Portugal \\ Ilda Freire-Ribeiro ${ }^{3}$ \\ Professora do Instituto Politécnico de Bragança / Bragança, Portugal
}

Recebido em: 10/05/2020

Aceito em: 12/05/2020

\section{Resumo}

O texto apresentado é de natureza teórica e procura analisar e situar os contributos da supervisão pedagógica para a formação docente em Portugal, desde que o conceito "supervisão" foi pela primeira vez apreciado na legislação nacional (PORTUGAL, 1990). Elaboramos análise documental percorrendo 30 anos da formação inicial em Portugal (1990-2020), desde o aparecimento do conceito em documentos normativos portugueses. Ao longo desta análise focar-nos-emos em aspetos que se prendem com a definição do conceito de supervisão, com a sua linha evolutiva no campo pedagógico e com abordagens de natureza teórica, procurando enquadrá-lo na legislação portuguesa, uma vez que visamos clarificar algumas das diretrizes normativas, quanto ao sentido e quanto à sua aplicação na formação inicial de professores. Além disso, procuraremos trazer algumas publicações de referência de autores/as nacionais que muito contribuíram para a reflexão em torno do conceito de supervisão e dignificaram a formação inicial de professores.

Palavras-chave: Supervisão pedagógica. Formação inicial de professores. Contributos para a formação.

\begin{abstract}
The text presented is of a theoretical nature and seeks to analyze and situate the contributions of pedagogical supervision to teacher training in Portugal, since the concept "supervision" was first considered in national legislation (PORTUGAL, 1990). We carry out documental analysis covering 30 years of initial training in Portugal (1990-2020), since the concept appeared in Portuguese normative documents. Throughout this analysis we will focus on aspects related to the definition of the concept of supervision, with its evolutionary line in the pedagogical field and with theoretical approaches, seeking to fit it in Portuguese legislation, since we aim to clarify some of the normative guidelines and its meaning and application in initial teacher education. In addition, we will try to bring some reference publications by national authors who contributed to the reflection around the concept of supervision and dignified the initial teacher training in Portugal.
\end{abstract}

\footnotetext{
${ }^{1}$ E-mail: elza@ipb.pt

2 E-mail: asanches@ipb.pt

${ }^{3}$ E-mail: ilda@ipb.pt
} 
Keywords: Pedagogical supervision. Initial teacher training. Contributions to training.

\section{Resumen}

El texto presentado es de naturaleza teórica y busca analizar y situar las contribuciones de la supervisión pedagógica a la formación docente en Portugal, ya que el concepto de "supervisión" se consideró por primera vez en la legislación nacional (PORTUGAL, 1990). Llevamos a cabo un análisis documental que abarca 30 años de formación inicial en Portugal (1990-2020), ya que el concepto apareció en documentos normativos portugueses. A lo largo de este análisis nos centraremos en aspectos relacionados con la definición del concepto de supervisión, con su línea evolutiva en el campo pedagógico y con enfoques teóricos, buscando encajar en la legislación portuguesa, ya que nuestro objetivo es aclarar algunas de las pautas normativas, en cuanto al significado y su aplicación en la formación inicial del profesorado. Además, trataremos de traer algunas publicaciones de referencia de autores nacionales que contribuyeron mucho a la reflexión sobre el concepto de supervisión y dignificaron la formación inicial del profesorado.

Palabras clave: Supervisión pedagógica. Formación inicial del profesorado. Contribuciones a la formación.

\section{Introdução}

Ao longo do artigo aportamo-nos no tema contributos da supervisão pedagógica para a formação docente em Portugal e pretendemos fazer uma revisão da literatura sobre o conceito de supervisão, desde o seu aparecimento legislativo, com a publicação do Estatuto da Carreira dos Educadores de Infância e dos Professores dos Ensinos Básico e Secundário, regulado pelo Decreto-Lei n. 139-A/90, de 28 de abril de 1990 (PORTUGAL, 1990). Trata-se, portanto, de um estudo que, num primeiro momento, atende ao conceito de supervisão de uma forma mais abrangente e, posteriormente, evidencia-de que forma esse conceito é entendido no contexto pedagógico ao longo de 30 anos (1990-2020).

Pretendemos ainda problematizar o lugar da história da supervisão pedagógica no sistema de ensino superior, mais concretamente na área da formação inicial de professores, e compreender como se sedimentou o conceito e que papel (ou papéis) tem desempenhado, quer do ponto de vista de autores/as nacionais que convocamos para a análise, quer da legislação em Portugal sobre esta matéria. Neste enquadramento da sistematização de algumas questões em torno do tema apresentamos, assim, algumas publicações de autores/as nacionais que consideramos de referência no campo da supervisão, salientando alguns resultados de estudos e algumas reflexões daí decorrentes.

\section{Formação inicial de professores em Portugal: contextualização}

Efetivamente, o exercício da docência exige, segundo Estrela (2001, p. 120), "formação profissional longa e certificada" que legitime o "monopólio do exercício profissional" e que autorize uma "relativa autonomia do seu desempenho". Em Portugal, a formação docente compreende a formação 
inicial, a formação especializada e a formação contínua, previstas na Lei de Bases do Sistema Educativo (LBSE) (PORTUGAL, 1986). Para além da LBSE, também o Estatuto da Carreira Docente (ECD) salvaguarda a formação inicial de professores e, a esse respeito, no seu artigo 13ำ, na sua versão mais recente, expõe o seguinte:

1 - A formação inicial dos educadores de infância e dos professores dos ensinos básico e secundário é a que confere habilitação profissional para a docência no respectivo nível de educação ou de ensino.

2 - A formação inicial visa dotar os candidatos à profissão das competências e conhecimentos científicos, técnicos e pedagógicos de base para o desempenho profissional da prática docente nas seguintes dimensões:

a) Profissional, social e ética;

b) Desenvolvimento do ensino e da aprendizagem;

c) Participação na escola e relação com a comunidade educativa;

d) Desenvolvimento profissional ao longo da vida (FEDERAÇÃO NACIONAL DA EDUCAÇÃO, 2019, p. 19-20).

Neste sentido, sobre o sistema de formação em Portugal, a política do Governo é que a formação de professores contribua para uma melhoria da qualidade de ensino e das aprendizagens dos alunos e que esta melhoria resulte da contínua capacitação profissional dos professores ao longo da vida, sempre numa atitude reflexiva e investigadora, tornando-os profissionais da mudança (CAMPOS, 2002). Na verdade, as "políticas de formação têm vindo a evoluir da promoção de modelos escolarizantes" para "modelos contextualizados, isto é, centrados na transformação das práticas em contexto" (FORMOSINHO, 2009, p. 14). Todavia, quer estejamos a falar da formação inicial quer da formação contínua, "o terreno da formação de professores é atravessado por clivagens ideológicas que, não só determinam as condicionantes institucionais que o contextualizam, mas também influenciam decisivamente até o próprio conhecimento científico a que recorrem" (MESQUITA, 2013, p. 13).

A partir de 2005, com a publicação dos princípios reguladores de instrumentos para a criação do espaço europeu de ensino superior (PORTUGAL, 2005), colocou-se às instituições de formação de professores o desafio de assumirem uma nova reorganização dos cursos seguindo os princípios da Declaração de Bolonha ${ }^{4}$, assinada em 19 de junho de 1999. Perante a mudança de paradigma no âmbito da formação inicial, o Decreto-lei no 42/2005, de 22 de fevereiro clarifica que

o estudante desempenha o papel central, quer na organização das unidades curriculares, cujas
horas de contacto assumirão a diversidade de formas e metodologias de ensino mais adequadas,
quer na avaliação e creditação, as quais considerarão a globalidade do trabalho de formação do
aluno, incluindo as horas de contacto, as horas de projecto, as horas de trabalho de campo, o
estudo individual e as actividades relacionadas com avaliação, abrindo-se também a actividades
complementares com comprovado valor formativo artístico, sócio-cultural ou desportivo (p.
1494).

\footnotetext{
${ }^{4}$ Complementada pelos comunicados de Praga, Berlim, Bergen, Londres, Lovaina, Budapeste, Viena, Bucareste e Yerevan. A designação comum que sintetiza estas declarações é o Processo de Bolonha, cujo objetivo é promover a mobilidade e cidadania europeia pela harmonização do ensino nos diversos países signatários e que um diploma de qualquer universidade de um Estado-membro possa ser automaticamente reconhecido nos restantes.
} 
Em função do enquadramento legal, o ensino superior em Portugal reestruturou-se, desde 2006/2007, ao "abrigo da Declaração de Bolonha" e passou a ser "ministrado em institutos politécnicos e universidades, de natureza pública, privada" e "cooperativa" (PORTUGAL, 2007a, p. 9). A certificação para a docência é então de responsabilidade das instituições de formação (universidades e institutos politécnicos). No quadro da Declaração de Bolonha, o ensino superior organiza-se em três ciclos de formação: licenciatura, mestrado e doutoramento. O Governo fundamenta esta paradigmática transição defendendo que se deve colocar de parte um "ensino fundado na ideia de transmissão de conhecimentos" em prol de um "sistema baseado no desenvolvimento de competências e na adopção do sistema de créditos curriculares (ECTS - European Credit Tranfer and Accumulation System ${ }^{5}$ )" (PORTUGAL, 2007a, p. 26). As universidades conferem o grau de licenciado, de mestre e de doutor, enquanto os institutos politécnicos conferem o de licenciado e o de mestre. O XVII Governo constitucional (12 de março de 2005 - 26 de outubro de 2009), com a concretização da Declaração de Bolonha, pretendeu aperfeiçoar a qualificação dos portugueses no espaço europeu, nomeadamente, "melhorar a qualidade e a relevância das formações oferecidas; melhorar a mobilidade dos estudantes; promover a internacionalização das formações; e abrir as instituições à sociedade e à economia" (PORTUGAL, 2007a, p. 25). Contudo, continua-se, inequivocamente, perante o reforço do sistema de ensino superior binário: "o ensino politécnico concentrar-se-á em formações vocacionais e em formações técnicas avançadas de 1을 ciclo, orientadas profissionalmente" e "as universidades deverão reforçar a oferta de formações científicas sólidas, especialmente de pós-graduações, juntando esforços e competências de unidades de ensino e investigação" (PORTUGAL, 2007a, p. 27).

Os ciclos de estudos conducentes ao grau de mestre que conferem habilitação profissional para a docência sofreram alterações significativas a partir da publicação do Decreto-Lei no 43/20076 , de 22 de fevereiro que, estabeleceu o alargamento dos domínios de habilitação do docente generalista, passando a incluir a habilitação conjunta para a educação pré-escolar e para o $1^{\circ}$ ciclo do ensino básico ou a habilitação conjunta para os $1^{\circ}$ e $2^{\circ}$ ciclos do ensino básico. 0 mesmo Decreto-Lei determina que a titularidade da habilitação profissional para a docência generalista, na educação pré-escolar e nos $1^{\circ}$ e $2^{\circ}$ ciclos do ensino básico é "conferida a quem obtiver tal qualificação através de uma licenciatura em Educação Básica, comum a quatro domínios possíveis de habilitação nestes níveis e ciclos de educação e

\footnotetext{
${ }^{5}$ O European Credit Transfer and Accumulation System (ECTS) e a escala europeia de classificações permite facilitar a mobilidade e as creditações da formação obtida em qualquer dos países aderentes.

${ }^{6}$ Determinou a posse de habilitação profissional como condição para o exercício da função docente, sendo que os cursos que qualificam profissionalmente são os mestrados em ensino, nos termos fixados pelo referido Decreto-Lei, complementado pelo Decreto-Lei no 220/2009, de 8 de setembro e pela Portaria no 1189/2010, de 17 de novembro.
} 
ensino, e de um subsequente mestrado em Ensino, num destes domínios" (p. 1320).

Estipulou-se que o curso de mestrado na especialidade de educação pré-escolar e ensino do 1을 ciclo do ensino básico teria 90 créditos, assim distribuídos:

1. formação educacional geral -5 a 10 unidades de crédito;

2. didácticas específicas -25 a 30 unidades de crédito;

3. prática de ensino supervisionada -40 a 45 unidades de crédito;

4. formação na área da docência - 0 a 5 créditos.

Os 120 créditos estavam previstos para o mestrado na especialidade de ensino do 10 e 2 o ciclos do ensino básico, atribuindo-se a seguinte percentagem às diferentes componentes da formação:

1. formação educacional geral $-5 \%$;

2. didácticas específicas $-20 \%$;

3. prática de ensino supervisionada $-45 \%$;

4. formação na área da docência - $25 \%$.

Este regime jurídico de habilitação profissional para a docência entrou em vigor no ano letivo de 2007-2008. Posteriormente, com a publicação do Decreto-Lei no 79/2014, de 14 de maio, é aprovado o novo regime jurídico da habilitação profissional para a docência na educação pré-escolar e nos ensinos básico e secundário. Neste Decreto-Lei assinala-se o aumento da duração dos mestrados em Educação Pré-Escolar e em Ensino do 1ํ Ciclo do Ensino Básico de dois para três semestres, o aumento da duração do mestrado conjunto em Educação Pré-Escolar e Ensino do 1 Ciclo do Ensino Básico de três para quatro semestres e a fixação em quatro semestres da duração dos restantes mestrados. Também regulamenta o desdobramento do mestrado em Ensino do 1ㅇ e do 2ำ Ciclos do Ensino Básico separando a formação de docentes do 2을 Ciclo de Português, História e Geografia de Portugal da formação de docentes do 2을 em Matemática e Ciências Naturais, desdobramento este que está ajustado aos grupos de recrutamento e que permite reforçar a formação na área da docência e à eliminação de mestrados sem correspondência com os grupos de recrutamento.

Como vimos, o próprio sistema de ensino convenciona que o primeiro contacto com os saberes profissionais de formação para a docência se faça na formação inicial, considerada como uma fase de preparação formal e intencional vivida numa instituição de formação de professores, na qual o futuro professor começa por realizar as suas práticas de ensino (MARCELO GARCÍA, 1999). Facto que poderá significar que a pessoa em formação "enfrenta um conjunto de experiências significativas que podem potenciar a sua ação profissional no futuro" (MESQUITA, 2013, p. 15). Contudo, não deixa de ser verdade que, quando o candidato a professor chega a uma instituição de ensino superior, já teve a oportunidade 
de observar "vários professores diariamente", imitando-os e moldando-se a eles "em actividades de role play espontâneo" (FORMOSINHO, 2001, p. 50). Neste sentido, percebe-se que a socialização para a profissão de professor, decorre, em primeira instância, no exercício do ofício de aluno e, mais tarde, concretiza-se com a formação inicial. Estes dois processos podem ser promotores de práticas (trans)formadoras ou reprodutoras da ação do futuro professor, sendo muito importante atender aos "princípios fundamentais na humanização das práticas educacionais, da formação, do desenvolvimento e da sua supervisão" (ROCHA; SÁ-CHAVES, 2012, p. 4).

\section{Supervisão pedagógica: emergência legislativa e evolução do conceito}

Reportamos uma breve análise da Lei de Bases do Sistema Educativo (LBSE) ${ }^{7}$, nomeadamente à Lei $n$ ㅇ 46/86, de 14 de outubro, uma vez que contribuiu para a reorganização do sistema educativo através da subdivisão em educação pré-escolar, escolar e extra-escolar e, determinou aspetos como a universalidade, a obrigatoriedade e a gratuidade por um período escolar de nove anos, correspondente a toda a duração do ensino básico ${ }^{8}$. Neste contexto, a educação escolar passou a compreender os ensinos básico, secundário e superior.

Num contexto de reforma educativa, o Governo optou por fazer aprovar um estatuto da função docente, no qual incluiu disposições relativas a toda a vida profissional do docente, desde o momento do seu recrutamento até à cessação de funções. De uma forma implícita, o termo supervisão foi, pela primeira vez, contemplado na legislação nacional, no no 1 do artigo 56으, do Decreto-Lei no 139-A/90, ao salientar que "a capacitação para o exercício de outras funções educativas adquire-se, nos termos do disposto no artigo 33으 da LBSE, pela frequência com aproveitamento de cursos especializados realizados em instituições de formação para o efeito competentes". Por sua vez, a formação do pessoal docente desenvolve-se de acordo com os princípios gerais constantes do no 1 do artigo 30ㅇ da LBSE, competindo ao Ministro da Educação o respetivo planeamento, coordenação e avaliação global. Assim, a leitura do no 1 do artigo 30을 da LBSE, ao estabelecer os princípios gerais sobre a formação de educadores e professores, assenta no seguinte:

a) Formação inicial de nível superior, proporcionando aos educadores e professores de todos os níveis de educação e ensino a informação, os métodos e as técnicas científicos e pedagógicos de base, bem como a formação pessoal e social adequadas ao exercício da função;

b) Formação contínua que complemente e actualize a formação inicial numa perspectiva de

\footnotetext{
${ }^{7}$ A Lei de Bases do Sistema Educativo estabelece o quadro geral do sistema educativo português e define-se como sendo o referencial normativo das políticas educativas que visam o desenvolvimento da educação e do sistema educativo.

${ }^{8}$ Em 2009 (a LBSE foi alterada pela Lei n.o 65/15, de 3 de julho (http://www.cnedu.pt/pt/noticias/cne/1039-lei-de-bases-dosistema-educativo), sendo estabelecido o regime da escolaridade obrigatória para as crianças e jovens que se encontrassem em idade escolar e a consagração da universalidade da educação pré-escolar para as crianças a partir dos 5 anos de idade.
} 
educação permanente;

c) Formação flexível que permita a reconversão e mobilidade dos educadores e professores dos diferentes níveis de educação e ensino, nomeadamente o necessário complemento de formação profissional;

d) Formação integrada quer no plano da preparação científico-pedagógica quer no da articulação teórico-prática;

e) Formação assente em práticas metodológicas afins das que o educador e o professor vierem a utilizar na prática pedagógica;

f) Formação que, em referência à realidade social, estimule uma atitude simultaneamente crítica e actuante;

g) Formação que favoreça o estimule a inovação e a investigação, nomeadamente em relação com a actividade educativa;

h) Formação participada que conduza a uma prática reflexiva e continuada de auto-informação e auto-aprendizagem (PORTUGAL, 1990, p. 3075).

A legislação portuguesa compreende, assim, três modalidades de formação para o pessoal docente, nomeadamente a formação inicial, a formação especializada e a formação contínua, previstas, respectivamente, nos artigos 31은 33ㅇe e 35으, da LBSE (PORTUGAL, 1990). No que à formação inicial de educadores de infância e de professores dos ensinos básico e secundário diz respeito, o artigo 31으 da LBSE expressa o seguinte:

1 - Os educadores de infância e os docentes dos ensinos básico e secundário adquirem qualificação profissional em cursos específicos destinados à respectiva formação, de acordo com as necessidades curriculares do respectivo nível de educação e ensino, em escolas superiores de educação ou em universidades que disponham de unidades de formação próprias para o efeito, nos termos a seguir definidos:

a) A formação dos educadores de infância e dos professores do 10 e 20 ciclos do ensino básico realiza-se em escolas superiores de educação;

b) A formação dos educadores e dos professores referidos na alínea anterior pode ainda ser realizada em universidades, as quais, para o efeito, atribuem os mesmos diplomas que os das escolas superiores de educação;

c) A formação de professores do 3o ciclo do ensino básico e de professores do ensino secundário realiza-se em universidades.

2 - A formação dos professores de disciplinas de natureza profissional, vocacional ou artística dos ensinos básico ou secundário adquire-se em cursos profissionais adequados, que se ministram em escolas superiores, complementados por uma formação pedagógica.

3 - Podem também adquirir qualificação profissional para professores do 3 ciclo do ensino básico e para professores do ensino secundário os licenciados que, tendo as habilitações científicas requeridas para o acesso à profissionalização no ensino, obtenham a necessária formação pedagógica em curso adequado.

4 - Os cursos de formação de professores do $2^{\circ}$ e 3 o ciclos do ensino básico a de professores do ensino secundário serão cursos de licenciatura.

5 - Os cursos de licenciatura para formação de professores do 20 ciclo do ensino básico realizados nas escolas superiores de educação organizam-se nos termos do no 7 do artigo 13‥

6 - As escolas superiores de educação e as instituições universitárias podem celebrar convénios entre si para a formação de educadores e professores. 
Ao longo de 30 anos de vigência, o Estatuto da Carreira Docente (ECD) teve várias alterações, sendo, muitas vezes, árdua a tarefa de saber qual a versão mais atualizada do diploma. Na Figura 1 apresentamos a visão retrospetiva das várias alterações a que foi sujeito o ECD, entre 1990 e 2016.

\section{Figura 1}

Estatuto da Carreira Docente (1990-2016)

\section{A CARREIRA DOCENTE E A SUA ESTRUTURA}

1990

O Decreto-Lei no 139-A/90 de 28 de abril aprova o Primeir Estatuto da Carreira Docente - Estatuto da função docente, com disposições relativas a toda a vida profissional do docente, desde o momento do seu recrutamento até à cessação de funções. O Estatuto remete, no seu artigo 35o, para o DecretoLei $\mathrm{n} 0409 / 89$, de 18 de novembro, relativo à estrutura da carreira docente.

\section{ALTERAÇÃO AOS ARTIGOS 56ㅇ E 57음 DO DECRETO-LEI №139-A/90}

1997 No dia 23 de abril é publicado Decreto-Lei no95/97. São alterados os artigos 56o (qualificação para o exercício de outras funções educativas) e 570 (exercício de outras funções educativas).

ALTERAÇÃO DE VÁRIOS ARTIGOS DO DECRETO-LEI №139-A/90

1998

No dia 2 de janeiro é publicado Decreto-Lei no 1/98.

DECLARAÇÃO DE INCONSTITUCIONALIDADE DA NORMA CONSTANTE DOS №s 2 E 3 DO ARTIGO 370

2001

No dia 4 de abril é publicado o Acórdão no153/2001. É declarada a inconstitucionalidade, com força obrigatória geral, da norma constante do artigo 37.․, n.os 2 e 3, do Decreto-Lei n.o 139-A/90, na medida em que exclui da contagem do tempo de serviço efectivo prestado em funções docentes as ausências do trabalho determinadas pelo exercício do direito à greve.

DECLARAÇÃO DE INCONSTITUCIONALIDADE DA NORMA CONSTANTE DA ALÍNEA A DO NÚMERO 1 DO ARTIGO 22은

2002

No dia 10 de outubro é publicado o Acórdão no 345/2002.

REVOGAÇÃO DO ARTIGO 123. DO DECRETO-LEI №139-A/90

$2003 \quad$ No dia 27 de fevereiro é publicado o Decreto-Lei no 35/2003.

ALTERAÇÃO DOS ARTIGOS 80. E 81. E REVOGAÇÃO DOS ARTIGOS 104., 118., 120. E 127.0 DO DECRETO-LEI №139-A/90

2005 No dia 29 de dezembro é publicado o Decreto-Lei no 229/2005 e no dia 29 de dezembro é publicado o Decreto-Lei no 229/2005.
REVOGAÇÃO DO ARTIGO 81.ㅇ DO DECRETO-LEI №139-A/90

2006

No dia 13 de novembro é publicado o Decreto-Lei no $224 / 2006$.

ALTERAÇÃO DE VÁRIOS ARTIGOS DO DECRETO-LEI №139-A/90

2007

No dia 19 de janeiro é publicado Decreto-Lei no15/2007 e no dia 15 de fevereiro é publicado Decreto-Lei no35/2007.

ALTERAÇÃO DE VÁRIOS ARTIGOS DO DECRETO-LEI №139-A/90

2009

No dia 30 de setembro é publicado Decreto-Lei no 270/2009. São alterados os artigos 16.ㅇ, 22.․, 31.ㅇ, $37 . \circ$, 38.ㅇ, 48.ㅇ, 63.ㅇ, 69.ㅇ e 111.․․

ALTERAÇÃO DE VÁRIOS ARTIGOS DO DECRETO-LEI №139-A/90

2010

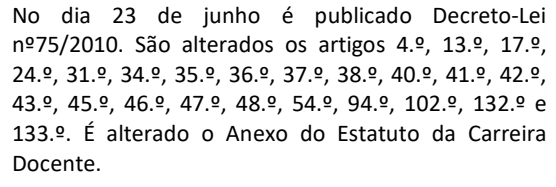

ALTERAÇÃO DE VÁRIOS ARTIGOS DO DECRETO-LEI №139-A/90

2012

No dia 21 de fevereiro é publicado Decreto-Lei no 41/2012. São alterados os artigos 31., 37.․, 40., 41., 42., 43.ㄴ, 45.ㅇ, 46.ํ, 47.ㅇ, 48.ㅇ e 100.․ É aditado o artigo $45 .^{\circ}-\mathrm{A}$.

ALTERAÇÃO DE VÁRIOS ARTIGOS DO DECRETO-LEI №139-A/90

2013

No dia 22 de outubro é publicado o Decreto-Lei no $146 / 2013$ e no dia 28 de novembro é publicada a Lei no $80 / 2013$.

ALTERAÇÃO DE VÁRIOS ARTIGOS DO DECRETO-LEI №139-A/90

2016

No dia 28 de abril é publicado a Lei no12/2016 (revogado o artigo 640-A) e no dia 17 de junho é publicada a Lei $n=16 / 2016$ (é alterada a redação do artigo 2.ㅇ e são revogados a alínea f) do $n .0$ e es n.os 7, 8, 9 e 10 do artigo 22.9 ).

Fonte: Elaboração própria. 
Como se observa na figura o ECD sofreu várias alterações e, em 1997, com a publicação do Decreto-Lei no 95/97, de 23 de abril, que fixou o regime jurídico da formação especializada, surgem listadas diferentes áreas de formação especializada. De entre as diferentes áreas, na alínea f) do ponto 1, do Artigo 3o podemos ler o seguinte: "Supervisão pedagógica e formação de formadores, visando qualificar para ao exercício de funções de orientação e supervisão da formação inicial e contínua de educadores e professores" (PORTUGAL, 1997, p. 1831). Outro marco legislativo deu-se com a publicação do Decreto-Lei no 15/2007, de 19 de janeiro, que tratou de rever o ECD no sentido de considerar relevante a valorização do trabalho dos professores e da organização das escolas, ao serviço da aprendizagem dos alunos. No preâmbulo assinala-se que, até à data, o ECD, anteriormente em vigor, diligenciou a degradação da imagem e função social dos professores e até permitiu que

as funções de coordenação e supervisão fossem desempenhadas por docentes mais jovens e com menos condições para as exercer. Daqui resultou um sistema que não criou nenhum incentivo, nenhuma motivação para que os docentes aperfeiçoassem as suas práticas pedagógicas ou se empenhassem na vida e organização das escolas (PORTUGAL, 2007b, p. 501).

Paralelamente, o conceito de supervisão tem sido acompanhado, refletido e difundido na literatura científica e, neste sentido, importa clarificar algumas questões ligadas à formação inicial de professores. Sabemos que a "pedagogia da formação se constrói na relação entre as mundividências do formador e dos formandos, supondo processos de construção colaborativa do saber educacional" (VIEIRA, 2006, p. 21) e que, conjuntamente, se deve refletir a supervisão no seu conceito, papéis e funções, uma vez que somos conscientes de que é um processo em desenvolvimento e em reedificação constantes (OLIVEIRA-FORMOSINHO, 2002a). A supervisão assume um papel preponderante no processo de formação sendo necessária uma implicação mais imbricada de todos os atores envolvidos (MARCHÃO; HENRIQUES, 2019; MESQUITA; MACHADO, 2019; MESQUITA; ROLDÃO, 2019; SANCHES, 2019).

\section{Em torno de um conceito: supervisão pedagógica}

São vários os autores que, em Portugal, têm vindo a contribuir para o desenvolvimento do pensamento sobre supervisão (ALARCÃO, 1982, 1992, 2000; ALARCÃO; TAVARES, 1987, 2003; VIEIRA, 1993, 2006, 2010; ALARCÃO; SÁ-CHAVES, 1994; OLIVEIRA-FORMOSINHO, 1997, 2002a, 2002b; SÁCHAVES, 2000, 2011, 2002; ALARCÃO; ROLDÃO, 2008; VASCONCELOS, 2009; VIEIRA; MOREIRA, 2011; ALARCÃO; CANHA, 2013; ALARCÃO, 2014; MOREIRA, 2015; MESQUITA; ROLDÃO, 2017, entre outros), 
acentuando dimensões que na sua complementaridade ajudam a compreender e a clarificar a forma como a supervisão tem vindo a ser entendida, bem como os traços evolutivos que nesse percurso histórico e epistemológico apresenta. O entendimento deste processo tende, na atualidade, para a assunção de uma orientação reflexiva e colaborativa, na qual o questionamento, a participação e a responsabilização dos diferentes intervenientes assumem importância.

Caracterizando a supervisão como uma ação de acompanhamento e monitorização, Alarcão e Canha (2013, p. 83) acentuam que deve integrar uma "orientação transformadora, de natureza reflexiva e autonomizante assente em interações que, concretizadas em dinâmicas de realização e sustentadas por atitudes de abertura e corresponsabilização, se afirmam como instrumentos ao serviço do desenvolvimento". A visão desenvolvimentista que se atribui à supervisão pressupõe o recurso a uma metodologia de natureza reflexiva, colaborativa e capacitante (MOREIRA, 2015). Estas dimensões são também valorizadas por Vieira (2009), acentuando a importância de articular as atividades supervisiva e pedagógica e que estas integrem uma visão emancipatória. No entender da autora trata-se de atividades "indissociáveis e que fazem parte de um mesmo projeto: indagar e melhorar a qualidade da ação educativa" (VIEIRA, 2009, p. 201).

Estas ideias assumem particular relevo ao reportar-nos à supervisão das atividades de iniciação à prática profissional previstas ao nível da formação inicial de professores/educadores, nas quais se procura promover e apoiar a sua formação e desenvolvimento, mas também a aprendizagem e o desenvolvimento das crianças/jovens que decorre a sua ação, bem como dos supervisores e das instituições, considerando as dinâmicas que nelas podem ser promovidas.

Assim, importa determo-nos sobre como, no atual Regime jurídico de habilitação profissional para a docência na educação pré-escolar e nos ensinos básico e secundário de Portugal, já antes referido (PORTUGAL, 2007c revisto por PORTUGAL, 2014), é perspetivado o processo de supervisão. É de considerar que, quer ao nível dos cursos de licenciatura quer ao nível dos cursos de mestrado, as atividades de iniciação à prática profissional são supervisionadas, embora a ação supervisiva mereça maior relevo neste último, sendo a componente de formação relacionada com o estágio designada como "prática de ensino supervisionada".

A iniciação à prática profissional deve ser organizada de modo a proporcionar aos formandos oportunidades de observação e colaboração em situações educativas e de prática supervisionada, bem como de se envolverem em experiências de planificação, ensino e avaliação. Prevê-se ainda, que essas atividades se constituam como oportunidades de desenvolvimento profissional dos formandos, 
permitindo-lhes desenvolver atitudes que contribuam para a melhoria da aprendizagem das crianças (PORTUGAL, 2014, arto 11ㅇ).

Quanto à concretização das atividades de iniciação à prática profissional prevê-se a celebração de protocolos de colaboração com as instituições cooperantes, visando regular o processo de cooperação. No que diz respeito aos professores/educadores que vão cooperar no desenvolvimento das práticas supervisivas são designados, no documento antes citado, como orientadores cooperantes e, pressupõese que possuam formação e experiência profissional adequadas às funções a desempenhar, e experiência profissional não inferior a cinco anos (PORTUGAL, 2014, arto 23ㅇ). Para a seleção dos orientadores cooperantes, constituem-se como critérios de preferência, possuírem: formação pósgraduada no nível educativo em que os formandos vão obter habilitação; formação especializada em supervisão pedagógica; e experiência profissional em supervisão (arto 23ำ). A responsabilidade pela orientação e monitorização da prática educativa surge, no documento citado, não limitada aos supervisores do estabelecimento de ensino superior e aos orientadores cooperantes, pois, prevê-se que, na avaliação do desempenho dos formandos, seja também tomada em consideração a informação prestada pelo coordenador do departamento curricular correspondente, ou pelo coordenador do conselho de docentes e, no caso do ensino particular ou cooperativo, pelo professor que assuma funções equivalentes (PORTUGAL, 2014, arto 24ㅇ). A cooperação interinstitucional é outra dimensão prevista, reconhecendo-se ser dever das escolas de ensino superior apoiar os docentes das instituições cooperantes, em particular dos orientadores cooperantes, no sentido do seu desenvolvimento profissional ao nível da formação dos futuros docentes (arto 23).

Estas diretrizes apontam para uma perspectiva de supervisão que, como defende Tracy (2002), ultrapassa os limites da sala de aula, prevendo uma abertura intencional aos contextos institucionais e à cultura envolvente. Remetem para uma ação supervisiva de qualidade, nem sempre fácil de assegurar para o que contribuem, entre outros fatores, a diversidade de tarefas que a escola de hoje exige aos docentes e o fraco investimento que ainda se verifica na formação no domínio da supervisão pedagógica (SANCHES, 2019).

Assim, e considerando o importante papel que as atividades de iniciação à prática profissional assumem na formação e desenvolvimento profissional dos futuros professores/educadores, deveria atribuir-se uma maior atenção às oportunidades criadas para os diferentes intervenientes exercerem com qualidade essa tarefa. A orientação a atribuir a esse processo é outra dimensão a considerar, sabendo que pode enveredar-se por uma ação supervisiva de estilo inspetivo e de controlo ou por um 
estilo colaborativo e emancipador, entendendo ser esta última, no quadro de uma aprendizagem ao longo da vida, a que melhor pode contribuir para a formação profissional e ética dos futuros professores/educadores.

\section{Supervisão: um processo de interações colaborativas}

A reflexão em torno do processo de supervisão leva-nos a equacionar os elementos a tomar em consideração para que assuma uma dinâmica formativa e reflexiva, de matriz desenvolvimentista e ecológica. Para tal, apoiamo-nos na perspetiva ecodesenvolvimentista defendida por Alarcão e Canha (2013), na qual os autores consideram dever atender-se às caraterísticas das atividades, das pessoas que as realizam (supervisores e supervisionados) e dos contextos em que se integram, bem como da influência que entre si exercem.

No que se refere às atividades, é de ter em conta que, para compreender as potencialidades e constrangimentos que o ambiente supervisivo apresenta, deve atender-se às suas finalidades, natureza e interrelações que apresentam, entre outros aspetos. Nestas atividades incluem-se as que os formandos desenvolvem com as crianças, mas também as relacionadas com a ação supervisiva, nomeadamente as que se referem à observação, acompanhamento e monitorização da sua intervenção educativa.

Quanto às pessoas é de considerar a natureza das caraterísticas que apresentam, sabendo que, entre as entendidas como potencialmente facilitadoras de interações positivas, se encontram as relativas à manifestação de curiosidade, atenção, iniciativa, reação e persistência. Por sua vez, há outras caraterísticas que tendem a constituir-se como inibidoras de interação, como as que se relacionam com manifestações de "impulsividade, agressividade, dispersão, desequilíbrio emocional, apatia, falta de atenção, irresponsabilidade, falta de interesse, insegurança e timidez" (ALARCÃO; CANHA, 2013, p. 77). É de considerar ainda outro tipo de caraterísticas, tendendo umas pessoas a preferirem enveredar mais pela concetualização e outras pela ação, bem como a gostarem umas mais do trabalho em grupo e outras do trabalho individual. É, ainda de atender às caraterísticas dos grupos, no sentido de responder às especificidades que cada um também apresenta, favorecendo a progressão de cada um dos intervenientes e, também do grupo.

No que diz respeito às caraterísticas das instituições é importante ter em atenção a sua organização e as dinâmicas de colaboração e de (inter)ação que criam. Existem escolas que apresentam um ambiente interacional gerador de bem-estar e de desenvolvimento pessoal e profissional, mas outras 
apresentam um clima de apatia e imobilismo que inibe a dinâmica supervisiva que se procura promover.

Quanto à comunicação e cooperação entre instituições são também diversos os ambientes interacionais que se criam, manifestando algumas, grande abertura ao diálogo e ao trabalho em parceria, enquanto outras tendem a manter-se fechadas, agindo de forma isolada.

A diversidade de situações e a complexidade que integra a ação supervisiva requer um continuado investimento para que sejam geradas dinâmicas colaborativas que se constituam, potencialmente, facilitadoras de aprendizagem e desenvolvimento de todos os intervenientes e dos contextos em que se integram. Requer-se, por isso, o recurso a um modelo de supervisão que atenda a essas especificidades, entre os quais, pode entender-se o de tipo não standard, defendido por Sá-Chaves (2002), o qual permite adotar um estilo de supervisão que se considere, em cada momento e situação, mais oportuno para responder à complexidade da situação e favorecer a progressão de cada um.

No que se refere aos estilos de supervisão pelos quais se pode pautar a ação supervisiva, Glikman (1985), de acordo com Alarcão e Tavares (2003), apresenta três, caraterizando-os como: diretivo, não diretivo e colaborativo. Cada um destes estilos supervisivos apresentam caraterísticas supervisivas diferentes. Numa supervisão de estilo diretivo, as preocupações do supervisor centram-se essencialmente em proporcionar orientações, estabelecer critérios e em condicionar as atitudes menos positivas dos formandos. No estilo não diretivo a ação do supervisor centra-se em escutar e atender às iniciativas dos formandos, encorajá-los a prosseguir, ajudá-los a clarificar as suas ideias e sentimentos, solicitando-Ihes explicações quando necessário. Já no estilo colaborativo, o supervisor ajuda aos formandos para encontrarem soluções, propõe-lhes sugestões e favorece a negociação. O recurso a um ou outro estilo de supervisão deve tomar como foco central apoiar e desafiar os formandos a progredirem ao nível profissional e pessoal, pautando-se por princípios éticos e de um desempenho profissional de qualidade.

Importa ter presente que a formação inicial é um momento relevante para o desenvolvimento de competências profissionais e pessoais essenciais para o desempenho da atividade docente, podendo entender-se a prática promovida nos contextos educativos como o primeiro passo na entrada para a profissionalização. De facto, as vivências proporcionadas pela prática educativa permitem aos formandos recorrer aos seus saberes e experiências para que possam tornar-se, e sentir-se, professores/educadores no espaço educativo e de formação em que se integrem e que se desenvolvam profissionalmente. A prática em contextos educativos pressupõe que a supervisão apoie esse processo, facilitando a integração dos formandos na dinâmica pedagógica da escola/agrupamento e a (re)construção de saberes sobre a mesma. 


\section{Natureza(s) supervisiva(s)}

A supervisão da prática educativa pode ocorrer de diferentes modos, podendo entender-se como sendo de natureza vertical, horizontal e intrapessoal ou seja, de autossupervisão (ALARCÃO; ROLDÃO, 2008).

A supervisão de natureza vertical diz respeito à interação estabelecida pelos supervisores (supervisor institucional, orientador cooperante e outros profissionais envolvidos nesse processo) com os formandos. Pela experiência e saberes profissionais que os supervisores detêm e pelo papel e responsabilidade que thes são atribuídos, assumem, em relação aos formandos, um lugar hierarquicamente superior, no que se refere às tomadas de decisão relativas ao processo formativo. São múltiplas as atividades que cabem aos supervisores realizar, centrando-se essencialmente em ajudar os formandos a desenvolverem-se e a promoverem uma ação educativa que favoreça a progressão dos seus alunos. Para tal, requer-se que os supervisores dominem conhecimentos ao nível das várias áreas e domínios de conteúdo, do desenvolvimento curricular e das metodologias de ensino-aprendizagem, mas que também conheçam os contextos e pautem as suas ações e relações por uma ética responsável. Neste âmbito, Mesquita e Roldão (2017, p. 75) defendem que "o supervisor deve ter uma consciência ética sobre a função que desempenha, agir atendendo a esses princípios e ajudar a promover uma atitude responsável dos formandos (supervisionados), conhecendo-os na sua individualidade e sem generalizar".

A supervisão de natureza horizontal tem a ver com a ação colaborativa e supervisiva que os formandos podem exercer entre si, a qual contribui para ampliar as possibilidades de conhecerem a realidade educativa e se desenvolverem pessoal e profissionalmente. Daí que a organização dos formandos em pares pedagógicos para o desenvolvimento das atividades de iniciação à prática profissional ou de prática de ensino supervisionada, como ocorre na instituição de formação em que nos integramos, pode entender-se como facilitadora de apoio supervisivo. Este representa uma mais-valia para a formação de cada formando, pelo olhar crítico e amigável que entre colegas é partilhado. Porém, para que este tipo de supervisão se constitua como prática de emancipação pessoal e de transformação social deve ultrapassar as lógicas e interesses individuais, investindo no desenvolvimento do grupo e questionamento do papel e da ação do professor/educador e dos contextos educativos.

A autossupersivão, sendo um processo de natureza intrapessoal, pressupõe a indagação e a responsabilização pessoal pelo investimento na mobilização de recursos que favoreçam o seu 
desenvolvimento profissional. Espera-se que, nesse processo, cada formando se sinta desafiado à autorreflexão, valorize o seu conhecimento, as suas experiências e ambições e que saiba orientar e gerir o seu percurso formativo, o que requer uma observação sistemática de si próprio (ALARCÃO; CANHA, 2013).

Em todo este processo merece prestar-se atenção aos receios e inseguranças que os formandos experienciam nos primeiros contactos com as instituições cooperantes, mas também ao processo supervisivo, pretendendo-se que supervisores e formandos se envolvam na construção de um ambiente interacional em que cada um se sinta desafiado à partilha de ideias e que usufrua da necessária confiança para partilhar receios e angústias, no sentido de se sentirem apoiados para superá-los e se envolverem na concretização de propostas inovadoras.

Nesta linha, acentua-se a importância da supervisão como atividade que pode proporcionar a articulação de diferentes olhares, nomeadamente o de cada um dos formandos e supervisores, no sentido de uma corresponsabilização pelo percurso formativo de cada um e do grupo. Por conseguinte, o foco da supervisão deixa de estar centrado no indivíduo, passando a centrar-se no grupo, podendo contribuir para a construção de comunidades de aprendizagem que ajudem a melhor conhecer e lidar com a realidade educativa e a (co)construir e (re)construir significados sobre a mesma (OLIVEIRAFORMOSINHO, 2002b).

\section{A reflexão no processo de supervisão}

Entre as estratégias de supervisão tem vindo a atribuir-se particular ênfase à reflexão, tendo os estudos desenvolvidos por Schön $(1983,1987)$ contribuído para uma crescente tomada de consciência da importância que este processo assume na construção de saberes sobre a prática profissional. Reconhece-se que, para tal, a reflexão deve ser orientada para o questionamento, a análise e a interpretação da prática educativa, nas múltiplas dimensões que a caraterizam, bem como para a progressiva emancipação dos formandos. Nesse processo, é de considerar que, como refere Sanches (2019, p. 156), "o potencial emancipatório da reflexão pode variar em função da orientação e nível de aprofundamento que integra". Neste âmbito, importa retomar aqui os três tipos de reflexão que Vieira (2010), baseando-se em Van Manen (1997), aponta e, em nosso parecer, ajudam a compreender os processos de reflexão promovidos ao nível da formação inicial de professores/educadores: reflexão de nível técnico, de nível prático e de nível crítico/emancipatório. A reflexão de nível técnico centra-se, particularmente, na concretização dos objetivos definidos e em assegurar a melhoria do desempenho 
dos formandos. A reflexão de nível prático pressupõe a análise de ideias, predisposições, valores e os modos de concretização das práticas educativas promovidas pelos formandos. A reflexão de nível crítico, ou emancipatório, promove a indagação e a problematização das práticas educativas, abrangendo a dimensão ética, social e política e integrando uma abordagem autonomizante dos formandos e dos alunos com quem são desenvolvidas essas práticas.

Sublinha-se a importância que a reflexão pode assumir na construção de conhecimento profissional, promovendo a análise de situações educativas, o confronto de saberes, teóricos e práticos, a negociação de sentidos, linguagens e tomadas de decisão, bem como a procura de respostas e soluções que se entendam pertinentes. Valoriza-se, também, "o trabalho colaborativo, reconhecendo-se a necessidade de conceber e orientar a ação supervisiva pautada pela construção partilhada de saberes, a assunção de responsabilidades, numa vivência democrática e emancipatória" (GONÇALVES; SANCHES, GUERREIRO; MARTINS; MESQUITA; MESQUITA; RODRIGUES; NOVO, 2019, p. 121).

Tal como defendem Marchão e Henriques (2019, p. 90) "as dificuldades que muitos futuros educadores/professores apresentam na formação inicial, quando se trata de construir quadros de reflexão, podem ser atenuadas se os supervisores conhecerem estratégias de promoção do pensamento crítico e as utilizarem de modo inteligente". Todavia, o desenvolvimento de processos de reflexão de qualidade é uma tarefa complexa, considerando Alarcão e Roldão (2008) que os resultados de um estudo desenvolvido com formandos da formação inicial revelam práticas de reflexão incipientes, bem como a dificuldade em refletir e em comunicar o teor das reflexões e a centração destas, sobretudo, nas práticas letivas. A parca experiência dos formandos e o facto de sentirem que estão a ser avaliados, são fatores que, no entender de Vieira (2010), também contribuem para que a reflexão nem sempre decorra com a qualidade desejada.

Sublinha-se a importância de enveredar por uma postura que integre uma abordagem indagadora e interpretativa da prática educativa e que encoraje os formandos a uma ação investigativa que contribua também para o seu desenvolvimento profissional e pessoal, no quadro de uma aprendizagem em continuidade ao longo da vida.

Sendo o supervisor institucional e o orientador cooperante profissionais experientes devem, como sugere Sá-Chaves (2002), diligenciar reflexões conjuntas que promovam a compreensão das situações na complexidade que as caracteriza, pois, ao deixar-se acompanhar no "exercício dialogante com a situação, com os materiais e consigo mesmo, pelo candidato a professor permite[m] que, lado a lado, também este dialogue, questione e reflita" (SÁ-CHAVES, 2002, p. 166). Este processo pode ser entendido como de descoberta guiada, permitindo conhecer e aprender no decurso da reflexão. Pressupõe-se que a reflexão ocorra ao nível das fases de pré e pós ação e requer o recurso a registos da 
ação observada. O feedback proporcionado aos formandos deve ser também encarado como um diálogo reflexivo e não apenas com finalidade avaliativa, apesar de também incluir esta dimensão, pressupondo que se constitua num elemento orientador e regulador do processo formativo.

Nesta linha, sublinha-se e entende-se a reflexão como uma práxis que envolve observação, monitorização e avaliação e que pressupõe uma construção colaborativa de saberes. Sublinha-se ainda a importância de investir na qualidade dos processos de reflexão desenvolvidos, quer ao nível das atividades de iniciação profissional da licenciatura em educação básica, quer da prática de ensino supervisionada dos cursos de mestrado, no sentido de criar melhores oportunidades de aprendizagem e desenvolvimento dos futuros professores/educadores.

\section{Considerações finais}

A Declaração de Bolonha desencadeou vastas reformas nas instituições do ensino superior tanto a nível organizativo como estrutural, com implicações no processo de ensino, aprendizagem e avaliação, ao enfatizarem a tutoria universitária, pois envolvem a personalização desses processos e arrastam a opção por uma via de aprendizagem autónoma e cooperativa por parte dos formandos, conduzindo também à reconfiguração de papéis dos diferentes intervenientes. O papel do professor passa a ser o de orientador do processo de aprendizagem e facilitador da aquisição e desenvolvimento de competências básicas e profissionais, incrementando a sua autonomia, pensamento crítico e a reflexão sobre o seu próprio processo de aprendizagem. Este paradigma implica que os professores universitários se desloquem do pólo do ensino para o pólo da aprendizagem e que se preocupem não apenas com o ensinar, mas, também, com o fazer aprender. É necessário, por conseguinte, adaptar a organização, a planificação e os métodos de ensino e de avaliação aos diferentes modos e estilos de aprendizagem dos formandos e aos seus diversos interesses, motivações, capacidades e expectativas. Para tal, a supervisão tem de facilitar este processo.

Entendemos, assim, que os cenários supervisivos (ou natureza(s) supervisiva(s)) são decisivos(as) para facilitar a aprendizagem. A supervisão torna-se a pedra angular na formação inicial de educadores/professores e no desenvolvimento de competências. Percebemos que uma ação supervisiva mais colaborativa, formativa, crítica, emancipadora e desafiadora, fomenta uma melhor aprendizagem e o desenvolvimento de saberes, de capacidades, de atitudes, habilitando os formandos para um desempenho profissional mais competente, em situação de prática(s) em contexto.

Sublinhamos o amplo papel da reflexão em todo este processo supervisivo, bem como o papel de cada interveniente, valorizando a partilha, a construção e orientação colaborativa do conhecimento 
profissional, o apoio e o questionamento sustentado e contextualizado.

Concluímos referindo a ininterrupta necessidade de nos continuarmos a questionar: Qual o estilo de supervisão a adotar para facilitar ao máximo a apropriação de competências profissionais por parte dos futuros educadores/professores, cuja ação educativa se desenvolve em diferentes contextos e com diferentes tipos de alunos? Que estilo de supervisão, no entender dos futuros educadores/professores, pode favorecer este processo? Que modalidades de formação prática são mais eficazes? Em que medida o formando coloca (ou não) em questão a eficácia do trabalho do supervisor?

\section{Referências}

ALARCÃO, Isabel. A supervisão clínica. Um conceito e uma prática ao serviço da formação de professores. Revista Portuguesa de Pedagogia, XVI, p. 151-168, 1982.

ALARCÃO, Isabel. Desenvolvimento do pensamento de D. Schön e os programas de formação de professores. Cadernos CIDInE, n. 1, p. 5-22, 1992.

ALARCÃO, Isabel. Escola reflexiva e supervisão: uma escola em desenvolvimento e aprendizagem. In: ALARCÃO, Isabel (Org.). Escola reflexiva e supervisão: uma escola em desenvolvimento e aprendizagem. Porto: Porto Editora, 2009, p. 11-23.

ALARCÃO, Isabel. Desenvolvimento profissional, interação colaborativa e supervisão. In: MACHADO, Joaquim; MATIAS ALVES, José (Coords.). Coordenação, supervisão e liderança. Escolas, projetos e aprendizagens. Porto: Universidade Católica Editora, 2014, p. 22-35. E-book. Disponível em: http://www.uceditora.ucp.pt/resources/Documentos/UCEditora/PDF\%20Livros/Porto/Coordena\%C3\%A 7\%C3\%A30\%20Supervis\%C3\%A30\%20e\%20Lideran\%C3\%A7a.pdf. Acesso em: 18 fev. 2020.

ALARCÃO, Isabel; CANHA, Bernardo. Supervisão e colaboração: uma relação para o desenvolvimento. Porto: Porto Editora, 2013.

ALARCÃO, Isabel; ROLDÃO, Maria do Céu. Supervisão: um contexto de desenvolvimento. Mangualde: Edições Pedago, 2008.

ALARCÃO, Isabel; SÁ-CHAVES, Idália. Supervisão de professores e desenvolvimento humano. Uma perspetiva ecológica. In: TAVARES, José (Ed.). Para intervir educação. Contributos dos colóquios CIDInE. Aveiro: Edições CIDInE, 1994. p. 201-232.

ALARCÃO, Isabel; TAVARES, José. Supervisão da prática pedagógica: uma perspectiva de desenvolvimento e aprendizagem. 2. ed. Coimbra: Almedina, 2003.

CAMPOS, Bártolo Paiva. Políticas de formação de profissionais de ensino em escolas autónomas. Porto: Edições Afrontamento, 2002.

ESTRELA, Maria Teresa. Questões de profissionalidade e profissionalismo docente. In: TEIXEIRA, Manuela (Org.). Ser professor no limiar do séc. XXI. Braga: ISET, 2001, p. 113-141. 
FEDERAÇÃO NACIONAL DA EDUCAÇÃO. Estatuto da Carreira Docente (Com alterações até à Lei n.으 16/2016, de 17 de Junho) e Diploma da Avaliação do Desempenho (Decreto regulamentar n.o 26/2012, de 21 de Fevereiro). Porto: Federação Nacional da Educação, 2019. Disponível em: https://fne.pt/uploads/documentos/documento 1552058734 1908.pdf. Acesso em: 29 abr. 2020.

FORMOSINHO, João. A formação prática dos professores: da prática docente na instituição de formação à prática pedagógica nas escolas. In: CAMPOS, Bártolo Paiva (Org.). Formação profissional de professores no ensino superior. Porto: Porto Editora, 2001. p. 46-64.

FORMOSINHO, João (Coord.). Formação de Professores: aprendizagem profissional e acção docente. Porto: Porto Editora, 2009.

GASPAR, Maria Ivone; SEABRA, Filipa; NEVES Cláudia. A supervisão pedagógica: significados e operacionalização. Revista Portuguesa de Investigação Educacional, v. 12, p. 29-57, 2012. Disponível em: https://doi.org/10.34632/investigacaoeducacional.2012.3374. Acesso em: 18 mar. 2020.

GONÇALVES, Adorinda; SANCHES, Angelina; GUERREIRO, Carla; MARTINS, Cristina; MESQUITA, Cristina; MESQUITA, Elza; RODRIGUES, Maria José; NOVO, Rosa. Formação inicial de educadores e professores: percepções dos cooperantes sobre o processo de supervisão. In: MESQUITA, Elza; ROLDÃO, Maria do Céu; MACHADO, Joaquim (Orgs.). Prática supervisionada e construção do conhecimento profissional. 1. ed. Vila Nova de Gaia: Fundação Manuel Leão, 2019, p. 93-128

MARCELO GARCÍA, Carlos. Formação de professores para uma mudança educativa. Porto: Porto Editora, 1999.

MARCHÃO, Amélia; HENRIQUES, Hélder. Formação inicial de educadores e de professores, supervisão e pensamento crítico. In: MESQUITA, Elza; ROLDÃO, Maria do Céu; MACHADO, Joaquim (Orgs.). Prática supervisionada e construção do conhecimento profissional. Vila Nova de Gaia: Fundação Manuel Leão, 2019, p. 73-92.

MESQUITA, Elza. Competências do professor. Representações sobre a formação e a profissão. Lisboa: Edições Sílabo, 2013.

MESQUITA, Elza; MACHADO, Joaquim. Formação e reflexibilidade dos formandos na prática supervisionada. In: MESQUITA, Elza; ROLDÃO, Maria do Céu; MACHADO, Joaquim (Orgs.). Prática supervisionada e construção do conhecimento profissional. Vila Nova de Gaia: Fundação Manuel Leão, 2019. p. 41-72.

MESQUITA, Elza; ROLDÃO, Maria do Céu. Formação inicial de professores: a supervisão pedagógica no âmbito do processo de Bolonha. Lisboa: Edições Sílabo, 2017.

MESQUITA, Elza; ROLDÃO, Maria do Céu (2019). A supervisão como dispositivo de desenvolvimento profissional e transformação de práticas. In: MESQUITA, Elza; ROLDÃO, Maria do Céu; MACHADO, Joaquim (Orgs.). Prática supervisionada e construção do conhecimento profissional. Vila Nova de Gaia: Fundação Manuel Leão, 2019. p. 13-39.

MESQUITA, Elza; FORMOSINHO, João; MACHADO, Joaquim. Supervisão da prática pedagógica e colegialidade docente. A perspectiva dos candidatos a professores. Revista Portuguesa de Investigação Educacional, v. 12, p. 59-77, 2012. Disponível em: https://doi.org/10.34632/investigacaoeducacional. 2012.3375. Acesso em: 18 mar. 2020. 
MOREIRA, Maria Alfredo. A supervisão pedagógica como prática de transformação: o lugar das narrativas profissionais. Revista Eletrônica de Educação, São Carlos/SP, v. 9, n. 3, p. 48-63. 2015. Disponível em: http://hdl.handle.net/1822/40305. Acesso em: 16 mar. 2020.

OLIVEIRA-FORMOSINHO, Júlia. Em direção a um modelo ecológico de formação de educadores de infância. Inovação, v. 10, n. 1, p. 89-110, 1997.

OLIVEIRA-FORMOSINHO, Júlia. A interacção educativa na supervisão de educadores estagiários: um estudo longitudinal. In: OLIVEIRA-FORMOSINHO, Júlia (Org.). A supervisão na formação de professores I: da sala à escola. Porto: Porto Editora, 2002a. p. 121-143.

OLIVEIRA-FORMOSINHO, Júlia. A supervisão pedagógica da formação inicial de professores no âmbito de uma comunidade de prática. Revista do GEDEI, Infância e Educação: investigação e práticas, n. 4, p. 42 $68,2002 b$.

PORTUGAL. Decreto-lei no 139-A/90. Diário da República no 98/1990, 1ㅇ Suplemento, Série I de 199004-28. Disponível em: https://dre.pt/application/conteudo/411815. Acesso em: 28 abr. 2020.

PORTUGAL. Decreto-lei no 95/97. Diário da República no 95/1997, I Série-A, de 1997-04-23. Disponível em: https://www.dgae.mec.pt/?wpfb dl=995. Acesso em: 30 abr. 2020.

PORTUGAL. Decreto-Lei no 42/2005. Diário da República no 37/2005, Série I-A, de 2005-02-22. Disponível em: https://dre.pt/application/conteudo/606304. Acesso em: 30 abr. 2020.

PORTUGAL. Ministério da Educação. Educação e formação em Portugal. Lisboa, 2007a.

PORTUGAL. Decreto-lei no 15/2007. Diário da República no 14/2007, Série I de 2007-01-19b. Disponível em: https://dre.pt/application/conteudo/522638. Acesso em: 30 abr. 2020.

PORTUGAL. Decreto-lei no 43/2007. Diário da República, 1ạ série, no 38, de 2007-02-22c. Disponível em: https://dre.pt/application/conteudo/517819. Acesso em: 05 mai. 2020.

PORTUGAL. Decreto-Lei no 220/2009. Diário da República n 174/2009, Série I de 2009-09-08. Disponível em: https://dre.pt/application/conteudo/489254. Acesso em: 06 mai. 2020.

PORTUGAL. Decreto-lei no 79/2014. Diário da República, 1a série, no 92, de 2014-05-14. Disponível em: https://dre.pt/application/conteudo/25344769. Acesso em: 05 mai. 2020.

PORTUGAL. Lei no 46/86. Diário da República no 237/1986, Série I de 1986-10-14. Disponível em: https://dre.pt/application/conteudo/222418. Acesso em: 28 abr. 2020.

PORTUGAL. Lei no 65/2015. Diário da República no 128/2015, Série I de 2015-07-03. Disponível em: https://dre.pt/application/conteudo/67664945. Acesso em: 28 abr. 2020.

PORTUGAL. Portaria no 1189/2010. Diário da República no 223/2010, Série I de 2010-11-17. Disponível em: https://dre.pt/application/conteudo/308761. Acesso em: 28 abr. 2020.

ROCHA, João; SÁ-CHAVES, Idália. Entrevista a especialistas na área científica da supervisão: Professora Idália Sá-Chaves. Indagatio Didactica, v. 4, n.2, p. 4-39, jul. 2012. Aveiro: CIDTFF - Universidade de Aveiro. Disponível em: https://repositorio.ipv.pt/handle/10400.19/4272. Acesso em: 24 mar. 2020. 
ROLDÃO, Maria do Céu. Supervisão, conhecimento e melhoria: uma triangulação transformativa nas escolas? Revista Portuguesa de Investigação Educacional, v. 12, p. 7-28, 2012. Disponível em: https://doi.org/10.34632/investigacaoeducacional.2012.3373. Acesso em: 18 mar. 2020.

SÁ-CHAVES, Idália. A construção de conhecimento pela análise reflexiva da práxis. Lisboa: Fundação Calouste Gulbenkian, 2002.

SÁ-CHAVES, Idália. Formação, conhecimento e supervisão. Contributos na área de formação de professores e outros profissionais. 3. ed. Aveiro: Universidade de Aveiro/CDITFF, 2011.

SANCHES, Angelina. A supervisão pedagógica enquanto processo colaborativo de formação profissional. In: MESQUITA, Elza; ROLDÃO, Maria do Céu; MACHADO, Joaquim (Orgs.). Prática supervisionada e construção do conhecimento profissional. Vila Nova de Gaia: Fundação Manuel Leão, 2019. p. 147-163.

SCHÖN, Donald. The reflective practitioner: how professionals think in action. New York: Basic Books, 1983.

SCHÖN, Donald. Educating the reflective practitioner. New York: Jossey-Bass, 1987.

TRACY, Saundra. Modelos e abordagens. In: OLIVEIRA-FORMOSINHO, Júlia (Org.). A supervisão na formação de professores I: da sala à escola. Porto: Porto Editora, 2002. p. 19-92.

VASCONCELOS, Teresa. Prática pedagógica sustentada: cruzamento de saberes e de competências. Lisboa: Edições Colibri/Instituto Politécnico de Lisboa, 2009.

VIEIRA, Flávia. Supervisão. Uma prática reflexiva de formação de professores. Rio Tinto: Edições Asa, 1993.

VIEIRA, Flávia. Para uma visão transformadora da supervisão pedagógica. Educação \& Sociedade, Campinas, v. 30, n. 106, p. 197-217, abr. 2009. Disponível em: https://doi.org/10.1590/S010173302009000100010. Acesso em: 09 mai. 2020.

VIEIRA, Flávia. Formação reflexiva de professores e pedagogia para a autonomia: para a constituição de um quadro ético e conceptual da supervisão pedagógica. In: VIEIRA, Flávia; MOREIRA, Maria Alfredo; BARBOSA, Isabel; PAIVA, Madalena; FERNANDES, Isabel Sandra (Orgs.). No caleidoscópio da supervisão: imagens da formação e da pedagogia. Mangualde: Edições Pedago, 2006, p. 15-44.

VIEIRA, Flávia. Formação reflexiva de professores e pedagogia para a autonomia: para a constituição de um quadro ético e conceptual de supervisão. In: VIEIRA, Flávia; MOREIRA, Maria Alfredo; BARBOSA, Isabel; PAIVA, Madalena; FERNANDES, Isabel Sandra (Orgs.). No caleidoscópio da supervisão: imagens da formação e da pedagogia. 2 ed. Mangualde: Edições Pedago, 2010, p. 15-35.

VIEIRA, Flávia; MOREIRA, Maria Alfredo. Supervisão e avaliação do desempenho docente: para uma abordagem de orientação transformadora. Lisboa: Ministério da Educação/CCAP, 2011. Disponível em: http://www.ccap.min-edu.pt/docs/Caderno CCAP 1-Supervisao.pdf. Acesso em: 03 mai. 2020. 